\title{
CONSTITUENTS FROM ROOTS OF Maytenus distichophylla, ANTIMICROBIAL ACTIVITY AND TOXICITY FOR CELLS AND Caenorhabditis elegans
}

\author{
Shirley A. T. Morales ${ }^{a}$, Mariana G. de Aguilar ${ }^{a}$, Rafael C. G. Pereira ${ }^{a}$, Lucienir P. Duarte, ${ }^{\mathrm{a}, \text {,(1) }}$, Grasiely F. Sousa ${ }^{\mathrm{a}}$, Djalma \\ M. de Oliveira ${ }^{\mathrm{b}}$, Fernanda C. G. Evangelista ${ }^{c}$, Adriano P. Sabino ${ }^{c}$, Roberta O. Viana ${ }^{\mathrm{d}}$, Viviane S. Alves ${ }^{\mathrm{d}}$ and Sidney A. \\ Vieira-Filho $^{\mathrm{f}}$ \\ aDepartamento de Química, Instituto de Ciências Exatas, Universidade Federal de Minas Gerais, 31270-901 Belo Horizonte - MG, \\ Brasil

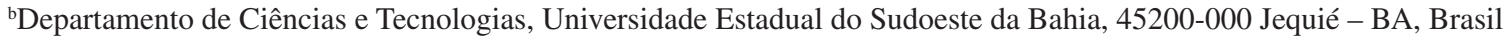 \\ 'Departamento de Análises Clínicas e Toxicológicas, Faculdade de Farmácia, Universidade Federal de Minas Gerais, $31270-901$ \\ Belo Horizonte - MG, Brasil \\ ${ }^{\mathrm{d}}$ Departamento de Microbiologia, Instituto de Ciências Biológicas, Universidade Federal de Minas Gerais, 31270-901 Belo \\ Horizonte - MG, Brasil \\ eDepartamento de Farmácia, Escola de Farmácia, Universidade Federal de Ouro Preto, 35400-000 Ouro Preto - MG, Brasil
}

Recebido em 31/03/2020; aceito em 09/06/2020; publicado na web em 15/07/2020

\begin{abstract}
Maytenus distichophylla is a medicinal species used in Northeast of Brazil. The hexane (HE), chloroform (CE), ethyl acetate (EAE) and methanol (ME) extracts and compounds from its roots were evaluated for their protective activity against Staphylococcus aureus and Candida albicans. The cytotoxicity for chronic myeloid leukemia (K562), acute monocytic leukemia (THP-1), and peripheral blood mononuclear cells of normal individuals (PBMC) cells was established by MTT method using etoposide as standard. The in vivo toxicity of samples was determined using Caenorhabditis elegans model. From HE and CE were isolated: friedelan-3-one (1), $\beta$-sitosterol (2), 3-oxo-olean-9(11),12-diene (3), a mixture of pristimerin (4) and 11 $\alpha$-hydroxylup-20(29)-en-3-one (5), 30-hydroxylup20(29)-en-3-one (6), friedelane-3,7-dione (7), tingenone (8) and triacylglycerol (9). The structures of 1-9 were confirmed by spectral data. All samples reduced the viability of $S$. aureus and present no effect against $C$. albicans. The HE, CE, mixture of $4 / \mathbf{5}$ and 8 reduced $75 \%$ of S. aureus viability. Cytotoxic effect for K562 and THP-1 cells was caused by compounds 1, 2 and $\mathbf{8}$. All samples displayed selectivity for leukemic cells and low toxicity to PBMC cells, suggesting their potential as anticancer agents. Extracts and compounds were non-toxic to L1 larvae of C. elegans. However, most of them reduced significantly young adult worm's survival, being considered as potential nematicides.
\end{abstract}

Keywords: Celastraceae; pentacyclic triterpenes; toxicity; K562 cells; THP-1 cells.

\section{INTRODUCTION}

Brazilian plant biodiversity, only having around 55,000 species catalogued of an estimated 550,000, represents an important research area. ${ }^{1}$ An example of plant biodiversity is the Celastraceae family, which comprises approximately 100 genera and more than 1200 species worldwide, many of them found mainly in South America, North Africa, and East Asia., ${ }^{2,3}$ The most abundant secondary metabolites isolated from species of the Celastraceae family, including those of the genus Maytenus, are the pentacyclic triterpenes (PCTT). Evidence has been gathered on the potential activities of PCTT, such as antiulcer and analgesic,${ }^{4,5}$ antiviral, ${ }^{6-9}$ antibacterial, ${ }^{10-12}$ antiparasitic,,${ }^{13,14}$ anti-inflammatory, ${ }^{5,15}$ antinociceptive,${ }^{16,17}$ antiangiogenic, ${ }^{18,19}$ and cytotoxicity. ${ }^{9,20,21}$ According to Saleem et al., the mechanism of action of PCTT on viruses, bacteria, and fungi is associated with cellular membrane rupture. ${ }^{22}$

In Brazil, Celastraceae family is mainly represented by five genera: Maytenus Juss, Salacia Mart, Goupia Reiss, Austroplenckia Lund, and Franhofera Mart. ${ }^{23}$ The genus Maytenus, one of the largest of the Celastraceae family, comprises 225 species, 76 of them recognized in Brazil, distributed in a variety of locations such as Amazonian and tropical forests, altitude fields, and the Cerrado, a vast tropical Brazilian savanna ecoregion., ${ }^{4,24}$ Plants of this genus are popularly used in Brazil to treat a diversity of illnesses, mainly gastrointestinal disorders. ${ }^{26}$ Among these species, Maytenus distichophylla (Figure 1S), popularly known as "paucolher", is a medium-sized tree up to 12 meters high. In traditional medicine, the infusion of $M$. distichophylla leaves and steam bark is used for the treatment of symptoms of chronic kidney disease. ${ }^{27}$ The compounds 3,16,21-trioxo-6 $\beta, 12 \alpha$-dihydroxyfriedel-1-ene, 3-oxofriedelane, 3,12-dioxofriedelane, 3 $\beta$-hydroxyfriedelane, 3-oxo29-hydroxyfriedelane, 3-oxo-12 $\alpha$-hydroxyfriedelane, 3-oxo-30hydroxyfriedelane, and a new triterpene named maytensifolone were previously described as constituents of $M$. distichophylla leaves..$^{28,29}$

As a continuation of our research on bioactive metabolites of the Celastraceae species used in folk medicine, in the present work, we describe the obtention of the hexane (HE), chloroform (CE), ethyl acetate (EAE), and methanol (ME) extracts from M. distichophylla roots. Aiming the isolation of non-polar constituents, $\mathrm{HE}$ and $\mathrm{CE}$ were fractioned by chromatography following methodology suggested by Matos $^{30}$ and Wagner \& Bladt. ${ }^{31}$ Nine compounds were isolated. The $\mathrm{HE}, \mathrm{CE}, \mathrm{EAE}$ and ME root extracts and the isolated compounds 1 to $\mathbf{8}$ were evaluated against Candida albicans and Staphylococcus aureus, their cytotoxic activity was assayed using the human cell lines K562 (chronic myeloid leukemia), THP-1 (acute monocytic leukemia), and PBMC (peripheral blood mononuclear cells of normal individuals), and their toxicity activity was evaluated in vivo using Caenorhabditis elegans. 


\section{EXPERIMENTAL}

\section{General experimental procedures}

The Fourier-transform infrared (FT-IR) spectra were recorded on a Perkin Elmer Frontier Single-Range MIR spectrometer with attenuated total reflection (ATR). The ${ }^{1} \mathrm{H}$ and ${ }^{3} \mathrm{C}$ (400.129 and $100.613 \mathrm{MHz}$, respectively) NMR spectra were performed on a Brüker DRX400 or DRX200 AVANCE spectrometers, using pure $\mathrm{CDCl}_{3}$. The chemical shifts were registered in $\delta$, TMS was used as an internal standard, and the coupling constants $(J)$ were registered in Hertz (Hz). Chromatographic columns (CC) were packed with silica gel 60 (70-230 Mesh). Thin layer chromatography (TLC) processes were developed using Merck silica gel 60 precoated plates.

\section{Plant material}

Maytenus distichophylla roots were collected in Brejo Novo ( $12^{\circ} 50^{\prime} 0.0^{\prime}$ S, $40^{\circ} 48^{\prime} 0.0^{\prime \prime} \mathrm{W}$ ), Jequié, Bahia, in July 2011. The species was identified by Dr. Guadalupe Edilma Lincona de Macedo, and a voucher specimen ( ${ }^{\circ}$ HUESB 2093) of the collected material was deposited in the Herbarium of the Department of Botany of UESB. The botanical material accessed was registered at Conselho de Gestão do Patrimonio Genético (CGEN/SISGEN), under number AFBF625.

\section{Extraction and isolation}

After drying at room temperature, the roots (1722 g) were ground on a mill. The resultant powder was subjected to continuous maceration with $3 \mathrm{~L}$ of hexane for 1 week and then filtered. This procedure was repeated two more times. These three filtrates were reduced using a rotatory evaporator at a temperature $\leq 40{ }^{\circ} \mathrm{C}$ and pooled. Then, by means of a similar procedure, the root powder residue was subjected to maceration using $3 \mathrm{~L}$ of chloroform, ethyl acetate, and methanol. Thus, hexane (HE, $11.4 \mathrm{~g}$ ), chloroform (CE, $28.4 \mathrm{~g}$ ), ethyl acetate (EAE, $56.3 \mathrm{~g}$ ), and methanol (ME, $181.5 \mathrm{~g}$ ) extracts were obtained. Part of the HE $(9.4 \mathrm{~g})$ was chromatographed using silica gel (500 g) CC using as eluents, hexane, chloroform, ethyl acetate and methanol, pure or in a mixture in increasing order of polarity, which produced 211 fractions (200 mL each). The following sequence was used for elution: hexane (fr 1-8), hexane:chloroform 9:1 (fr 9-48), hexane:chloroform 1:1 (fr 49-117), chloroform (fr 118-142), chloroform:ethyl acetate 1:1 (fr 143-171), ethyl acetate (fr 172-207) and methanol (fr 208-211). In accordance with their similar TLC profiles, the fractions were pooled to yield 15 groups. Thus, compound 1 (3.0 $\mathrm{mg}$ ) was isolated from group 4 (fr 75-82; hexane:chloroform 1:1;28.3 mg) after separation through a new $\mathrm{CC}$, using as eluents, hexane, chloroform, ethyl acetate and methanol, pure or in a mixture in increasing order of polarity (75 fr, $10 \mathrm{~mL}$ each). Group 5 (fr 118-124; chloroform, $198.6 \mathrm{mg}$ ) was re-chromatographed, using as eluents, hexane, chloroform, ethyl acetate and methanol, pure or in a mixture in increasing order of polarity (165 fr, $10 \mathrm{~mL}$ each), to yield 2 (fr 138-160; $26.0 \mathrm{mg}$ ) and 9 (fr 111-137; $10.0 \mathrm{mg}$ ). Group 8 (fr 146-152; chloroform:ethyl acetate $1: 1,2.9 \mathrm{~g}$ ) was passed through a new silica gel column, using as eluents, hexane, chloroform, ethyl acetate and methanol, pure or in a mixture in increasing order of polarity ( $145 \mathrm{fr}, 50 \mathrm{~mL}$ each), which furnished an additional amount of 2 ( $8.0 \mathrm{mg}), 3(21.0 \mathrm{mg})$, a mixture of $\mathbf{4}$ and $\mathbf{5}(8.8 \mathrm{mg}), \mathbf{5}(3.0 \mathrm{mg})$, and $\mathbf{6}(13.0 \mathrm{mg})$. Group 9 (fr 153-155; chloroform:ethyl acetate 1:1, $960.0 \mathrm{mg}$ ), after separation through a new CC using as eluents, hexane, chloroform, ethyl acetate and methanol, pure or in a mixture in increasing order of polarity (140 fr, $10 \mathrm{~mL}$ each), yielded 7 (5.0 mg). By means of similar procedure, part of the CE (24.4 g) was chromatographed using silica gel $(500 \mathrm{~g})$ producing 85 fractions ( $200 \mathrm{~mL}$ each). The fraction 47 (chloroform:ethyl acetate 7:3, $4.2 \mathrm{~g}$ ) were subjected to a new CC using as eluents, hexane, chloroform, ethyl acetate and methanol, pure or in a mixture in increasing order of polarity (fr $118,10 \mathrm{~mL}$ each) resulting in the isolation of compound 2 (fr 2123; chloroform; $17.0 \mathrm{mg}$ ) and $\mathbf{8}$ ( $\mathrm{fr}$ 42-47; chloroform:ethyl acetate $8: 2 ; 28.0 \mathrm{mg})$. The ethyl acetate and methanol extracts were not fractionated, but they were submitted to biological assays.

\section{Antimicrobial activity}

To evaluate a potential antimicrobial activity of samples from M. distichophylla roots against Staphylococcus aureus MRSA (ATCC 5923) and Candida albicans (SC5314), solutions ( $\mu \mathrm{g} \mathrm{mL}^{-1}$ ) of HE (27.4), CE (27.8), EAE (40.8), and ME (40.8) extracts and of the compounds 1 (11.0), 2 (16.1), 3 (20.0), the mixture of 4 and 5 (54.8), 5 (29.6), 6 (32.0), 7 (45.6), and 8 (56.0) were prepared using dimethyl sulfoxide (DMSO, Merck) as solvent. S. aureus MRSA was maintained in solid Luria-Bertani (LB) medium, and for assays, a colony was isolated and cultured for $18 \mathrm{~h}$ in liquid LB medium. C. albicans was maintained in brain heart infusion (BHI) medium and for the assays and isolated colony grown in a liquid BHI medium at $28{ }^{\circ} \mathrm{C}$, during $18 \mathrm{~h}$. The MTT (3-(4,5-dimethylthiazol-2-yl)-2,5diphenyltetrazolium bromide) (Sigma) tetrazolium reduction assay was used to evaluate microbial viability. ${ }^{32} S$. aureus or $C$. albicans $\left(2 \times 10^{6}\right.$ UFC $\left.\mathrm{mL}^{-1}\right)$ were prepared in M9 buffer and added to a 96-well Microtiter plate wells (final volume of $200 \mu \mathrm{L}$ ). To each well $2 \%(\mathrm{v} / \mathrm{v})$ of $M$. distichophylla extracts or compounds were added, the mixture was incubated for $24 \mathrm{~h}$ at $28^{\circ} \mathrm{C}$, and $20 \mu \mathrm{L}$ of MTT $\left(5.0 \mathrm{mg} \mathrm{mL}^{-1}\right)$ were added to the suspension. This mixture was incubated for 18 hours at $28{ }^{\circ} \mathrm{C}$. Culture medium was removed, $100 \mu \mathrm{L}$ of DMSO were added and the absorbance $(500 \mathrm{~nm})$ was determined to measure the cellular viability in comparison with negative control (microbial suspension not exposed to the tested substances).

\section{Cytotoxicity assay against leukemic cells}

Cytotoxic activity of extracts and compounds from M. distichophylla roots was carried out in vitro using the human cancer cell lines K562 (chronic myeloid leukemia, ATCC CCL-243) and THP-1 (acute monocytic leukemia, ATCC TIB-202), and PBMC (peripheral blood mononuclear cells) of healthy individuals. The in vitro activity was evaluated by plating $1 \times 10^{5}$ cells per well. After cell plating, microplates were incubated for at least $24 \mathrm{~h}$ at $37^{\circ} \mathrm{C}$ in the presence of $5 \% \mathrm{CO}_{2}$. Then, the wells were washed with culture medium (RPMI-1640 + 20\% inactivated fetal bovine serum + $2 \mathrm{mmol} \mathrm{L}{ }^{-1}$ L-glutamine $+100 \mathrm{U} \mathrm{mL}^{-1}$ penicillin) and incubated with samples at concentrations of $0.1,1.0,10.0$, and $100.0 \mu \mathrm{g} \mathrm{mL} \mathrm{m}^{-1}$. Untreated cells were used as negative controls. After incubation for $48 \mathrm{~h}$, the medium in each well was removed and discarded, and $100 \mu \mathrm{L}$ of $5 \%$ MTT were added to determine the cell viability. ${ }^{33,34}$ Colorimetric measurements were performed at $550 \mathrm{~nm}$ using a Spectramax M5e microplate reader. All experiments were performed in triplicate. The optical density of MTT-formazan formed in untreated control cells was taken as $100 \%$ viability. The results were expressed as the mean of the $\mathrm{IC}_{50}$ (the lethal drug concentration that reduced cell viability by $50 \%)$. $\mathrm{IC}_{50}$ values were calculated using OriginPro 8.0 software. The selectivity index (SI), which corresponds to the ratio between the cytotoxic activities to PBMC and the tumor cell lines, was also calculated. 


\section{Toxicity evaluation for Caenorhabditis elegans}

Caenorhabditis elegans N2 wild-type Bristol was purchased from Caenorhabditis Genetics Center (CGC), University of Minnesota, USA. The worms were maintained at $20{ }^{\circ} \mathrm{C}$ in nematode growth medium (NGM) seeded with Escherichia coli OP50, as described by Brenner. ${ }^{35}$

For the sample toxicity evaluation, the nematodes were maintained in M9 buffer $\left(\mathrm{KH}_{2} \mathrm{PO}_{4} 3.0 \mathrm{~g}, \mathrm{Na}_{2} \mathrm{PO}_{4} 6.0 \mathrm{~g}, \mathrm{NaCl} 5.0 \mathrm{~g}\right.$ in $1 \mathrm{~L}$ of water and $1 \mathrm{~mL}$ of $\mathrm{MgSO}_{4} 1 \mathrm{~mol} \mathrm{~L}^{-1}$ ) following a modified standard protocol. ${ }^{36,37}$ Then $C$. elegans larvae were exposed to extracts or compounds from $M$. distichophylla in a 96-well Microtiter ${ }^{\mathrm{TM}}$ plate in M9 buffer ( $200 \mathrm{uL})$ at $25^{\circ} \mathrm{C}$, by means of two systems: L1 larvae in M9 buffer for $24 \mathrm{~h}$ (acute exposure of L1) and L4 larvae with normal E. coli OP50 feed for 12 days. The exposures were realized at $25^{\circ} \mathrm{C}$ in the absence of normal feed with $E$. coli OP50 and DMSO was used as a negative control. After acute and chronic exposure of L1, the MTT method was used to evaluate the viability of C. elegans. ${ }^{38}$

The viability and survival evaluation were performed in 96-well plates using young adult $C$. elegans (L4) $(\mathrm{n}=10-15)$ in M9 buffer containing extract or compound in defined concentration, nystatin

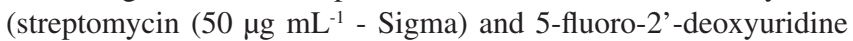
[FUDR ( $\left.80 \mu \mathrm{g} \mathrm{mL}^{-1}\right)$, Sigma]. This inhibitor of DNA synthesis was previously added to M9 buffer aiming to prevent $C$. elegans progeny production. ${ }^{39}$ The maximal sample concentration was used in the assays. After exposure of L4 larvae, the percentage of live larvae was used to evaluate survival. The $C$. elegans larvae were examined at $24 \mathrm{~h}$ intervals with a stereomicroscope and those not responding to mechanical stimulus with a platinum wire were considered dead..$^{37,40}$

\section{Statistical analysis}

The $\mathrm{IC}_{50}$ values were calculated using the OriginPro 8.0 software and analyzed using the program Sigma Stat version 2.03. The Shapiro-Wilk test was used to test the data for the normal distribution. Normally distributed data were analyzed by analysis of variance (ANOVA), followed by the Holm-Sidak multiple comparison test. In the case the data did not present a normal distribution, betweengroup comparisons were performed with ANOVA followed by the nonparametric Kruskal-Wallis test. The significance level was $p \leq 0.05$ for all statistical tests. S. aureus and C. albicans viability after extract or compound exposure were analyzed in GraphPad Prism ${ }^{\circledR}$ software 5.01. C. elegans survival curves were plotted, and estimation of differences (log-rank and Wilcoxon tests) in survival analyzed with the Kaplan-Meier method also using GraphPad Prism 5.01 software. A $p$-value of 0.05 was considered significant.

\section{RESULTS AND DISCUSSION}

\section{Phytochemical study}

Through phytochemical methods, eight compounds were isolated from $\mathrm{HE}$ and $\mathrm{CE}$ extracts of the $M$. distichophylla roots, being friedelan-3-one (1), $\beta$-sitosterol (2), 3-oxo-olean-9(11), 12-diene (3), $11 \alpha$-hydroxylup-20(29)-en-3-one (rigidenol) (5), 30-hydroxylup20(29)-en-3-one (6), friedelane-3,7-dione (7), tingenone (8), triacylglycerol (9) and a mixture of compounds $\mathbf{4}$ (pristimerin) and 5 (Figure 1).

The chemical structures of $\mathbf{1}$ to 9 (Figure 1) were established comparing the obtained spectral data (Figure $2 \mathrm{~S}$ to $25 \mathrm{~S}$ and Table $1 \mathrm{~S}$ ) with those found in literature. ${ }^{41-49}$

The ${ }^{1} \mathrm{H}$ NMR spectra of compound $\mathbf{1}$ and $\mathbf{7}$ showed seven singlets between $\delta_{\mathrm{H}} 0.77$ to 1.19 referring to seven methyl and one

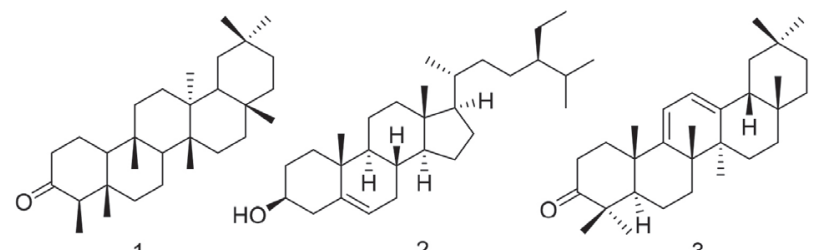

1

2

3

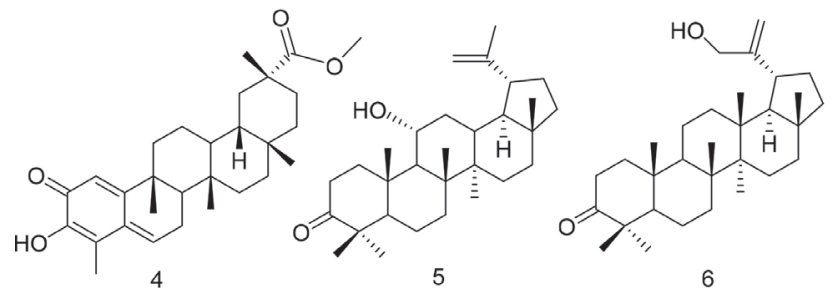

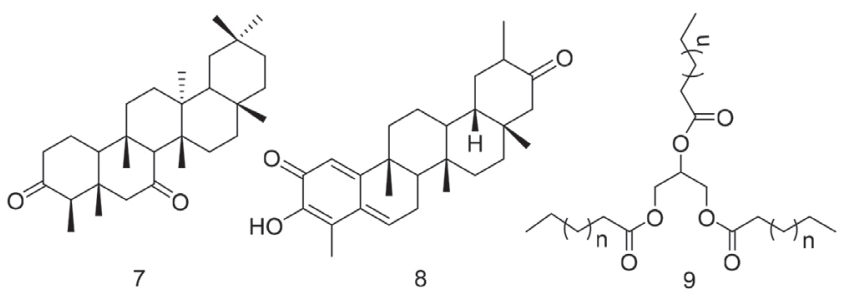

Figure 1. Chemical structures of compounds 1 to 9 from hexane and chloroform extracts of the Maytenus distichophylla roots

duplet referring to methyl $\mathrm{H}-23$, at the range $\delta_{\mathrm{H}} 0.87-0.89$, which are characteristic of friedelane skeleton triterpenes. ${ }^{41}$ Compound $\mathbf{1}$ was identified as friedelan-3-one and $\mathbf{7}$ as friedelane-3,7-dione, mainly due to carbonyl groups present in its structures (at $\delta_{\mathrm{C}} 213.2$ for $\mathbf{1}$ and $\delta_{\mathrm{C}} 211.0$ and $\delta_{\mathrm{C}} 210.5$ for 7 ). The compound 2 presented signal at $\delta_{\mathrm{H}} 5.35(1 \mathrm{H})$, characteristic of olefinic hydrogen and signal at $\delta_{\mathrm{H}} 3.52$ (1H) that corresponds to methine hydrogen attached to hydroxylated carbon atom. In the ${ }^{13} \mathrm{C}$ NMR spectrum of 2 , signals were observed at $\delta_{\mathrm{C}} 140.8(\mathrm{C}-5)$ and at $\delta_{\mathrm{C}} 121.7(\mathrm{C}-6)$ correspondent to olefinic carbons and signal at $\delta_{\mathrm{C}} 71.8(\mathrm{C}-3)$ associated to hydroxylated carbon, consistent with the steroid $\beta$-sitosterol. The compounds $\mathbf{3}, \mathbf{5}$ and $\mathbf{6}$ presented two signals between $\delta_{\mathrm{H}} 5.62$ to $\delta_{\mathrm{H}} 4.60$, characteristic of double bond hydrogen. Additionally, compounds $\mathbf{5}$ and $\mathbf{6}$ presented signals of hydroxylated carbon hydrogen at $\delta_{\mathrm{H}} 3.90(1 \mathrm{H})$ and $\delta_{\mathrm{H}} 4.12$ $(2 \mathrm{H})$, respectively. The ${ }^{13} \mathrm{C}$ NMR spectrum of compound 3 showed four signals of olefinic carbon, between $\delta_{\mathrm{C}} 152.3$ and $\delta_{\mathrm{C}} 117.5$, and the spectra of compounds $\mathbf{5}$ and $\mathbf{6}$ showed two characteristic signals of olefinic carbon $\left(\delta_{\mathrm{C}} 154.8\right.$ to $\left.\delta_{\mathrm{C}} 107.0\right)$. The spectra of $\mathbf{3}, \mathbf{5}$ and $\mathbf{6}$ also showed a carbonyl signal between $\delta_{\mathrm{C}} 217.8$ and $\delta_{\mathrm{C}} 218.7$ which was attributed to carbon C-3. These NMR signals are characteristic of lupane and oleanane skeleton, which allowed the identification of $\mathbf{3}, \mathbf{5}$ and $\mathbf{6}$ as 3-oxo-olean-9(11),12-diene, $11 \alpha$-hydroxylup-20(29)-en-3-one and 30-hydroxylup-20(29)-en-3-one, respectively. The ${ }^{1} \mathrm{H}$ NMR spectra of compounds $\mathbf{4}$ and $\mathbf{8}$ displayed signals at $\delta_{\mathrm{H}} 7.0(\mathrm{~d}, \mathrm{~J}=7.1 \mathrm{~Hz}, 1 \mathrm{H}), \delta_{\mathrm{H}} 6.5$ $(\mathrm{s}, 1 \mathrm{H})$ and $\delta_{\mathrm{H}} 6.3(\mathrm{~d}, \mathrm{~J}=7.1 \mathrm{~Hz}, 1 \mathrm{H})$, characteristic of quinonemethide triterpenes. Compounds $\mathbf{4}$ and $\mathbf{8}$ presented carbon signals between $\delta_{\mathrm{C}} 213.5$ and $\delta_{\mathrm{C}} 117.2$ corresponding to olefinic and carbonyl carbons. The presence of these signals allowed the identification of $\mathbf{4}$ and $\mathbf{8}$ as pristimerin and tingenone, respectively. Based on the signals at $\delta_{\mathrm{C}} 173.3$ and $\delta_{\mathrm{C}} 172.9(\mathrm{C}=\mathrm{O}), \delta_{\mathrm{C}} 68.9(\mathrm{CH}), \delta_{\mathrm{C}} 62.1\left(\mathrm{CH}_{2}\right), \delta_{\mathrm{C}} 14.1$ $\left(\mathrm{CH}_{3}\right)$ and the signals between $\delta_{\mathrm{C}} 34.3$ to $\delta_{\mathrm{C}} 22.7\left(\mathrm{CH}_{2}\right)$, compound 9 was characterized as triacylglycerol. After integration of the hydrogen signals (Figure 11S), and by the intensity of the signals of carbon atoms (Figure 12S) it was established that the $\mathbf{4}$ and $\mathbf{5}$ mixture consisted of $60 \%$ pristimerin (4) and $40 \%$ rigidenol (5).

Among the isolated compounds, the six triterpenes ( 3 to 8 ) and triacilglycerol (9) are reported for the first time for the $M$. distichophylla 
species. Friedelan-3-one (1) is abundant in leaves of species of the genus Maytenus, such as M. ilicifolia,${ }^{50,51} M$. salicifolia,${ }^{52}$ M. undata, ${ }^{3}$ and even in leaves of M. distichophylla. ${ }^{29}$ However, this compound is rare in roots of higher plants. On the other side, triacylglycerol (9) is uncommon in species of Maytenus. Mixtures of fatty acid short-chain-alkyl esters, such as 9, have been found in fruits of species of the Celastraceae family. ${ }^{53} \beta$-sitosterol (2) is a steroid commonly found in species of the Celastraceae family. There are works reporting $\mathbf{2}$ as recurrent in roots of Maytenus species, such as M. ilicifolia, ${ }^{51} M$. gonoclada ${ }^{54}$ M. acanthophylla $a^{55}$ and in the leaves of $M$. distichophylla. ${ }^{29}$ The triterpene 3-oxo-olean-9(11),12-diene (3) was previously isolated from species of the Celastraceae family, ${ }^{56}$ as well as the triterpene 6 was previously reported for the stems and branches of M. imbricata. ${ }^{57}$ Pristimerin (4) is a quinonemethide naturally found in species of the Celastraceae family that induces cytotoxicity in different cancer cell lines. ${ }^{58-60}$ Rigidenol (5) was previously reported as constituent of M. acanthophylla roots ${ }^{55}$ of $M$. chiapensis leaves ${ }^{61}$ and of $M$. cuzcoina root bark. ${ }^{62}$ Rigidenol isolated from M. cuzcoina and M. chiapensis exhibited anti-inflammatory activity and caused inhibitory effects on nitric oxide and prostaglandin E2 production in mouse macrophages (RAW 264.7) stimulated with bacterial endotoxin. ${ }^{61,62}$ In the present work, for the first time, rigidenol (5) is reported as a constituent of M. distichophylla roots. Rigidenol and 16ß-hydroxypristimerin from M. salicifolia exhibited activity against Helicobacter pylori, and nonpolar and polar extracts of this plant showed in vitro activity against oral pathogens such as Candida albicans, Streptococcus mutans, Streptococcus sanguinis, and Staphylococcus aureus. ${ }^{63}$ For these reasons, the mixture compounds $\mathbf{4}$ and $\mathbf{5}$ was also subjected to the biological assays in parallel with extracts and compounds isolated from $M$. distichophylla roots.

\section{Antimicrobial evaluation}

The activity of samples from $M$. distichophylla roots against $S$. aureus MRSA and C. albicans (SC5314) viability was evaluated by the MTT method. In this work, it was not observed significant antifungal activity against $C$. albicans of tested compound at maximal concentration when compared to DMSO used as control (Figure 2). It is important to highlight that it was not discarded possible activity against other pathogenic yeast and filamentous fungi.

Activity against $S$. aureus MRSA was observed at maximal tested concentrations and all samples demonstrating significant activity against $S$. aureus (Figure 2). The HE and CE extracts induced greater activity than ethyl acetate (EAE) and methanol (ME) extracts. HE and the mixture of $\mathbf{4}$ and $\mathbf{5}$ (Figure 2A), CE extract, compound $\mathbf{5}$ and $\mathbf{8}$ (Figure 2B) were the most active samples reducing $75 \%$ of $S$. aureus viability. Compounds $\mathbf{4}$ and $\mathbf{5}$ were isolated from $\mathrm{HE}$ and $\mathrm{CE}$ extracts, respectively. The HE and CE extracts induced greater activity than ethyl acetate (EAE) and methanol (ME) extracts. These results may be associated with the presence of pentacyclic triterpenes in the HE and CE extracts, for which antibacterial activity has been reported. ${ }^{10}$ Tingenone $(\mathbf{8})$ isolated from CE extract induced similar activity to CE extract suggesting that the activity of this crude extract may be associated with the presence of $\mathbf{8}$ (Figure 2B). There was no significant difference in $S$. aureus susceptibility between the more active compounds (Figure 2). Thus, the more active samples can be considered as potential candidates for in vivo assays involving $S$. aureus infections aiming to establish its efficacy.

\section{Cytotoxicity evaluation}

Due to the demand for new resources against diseases that involve complicated, invasive, and expensive treatments such as
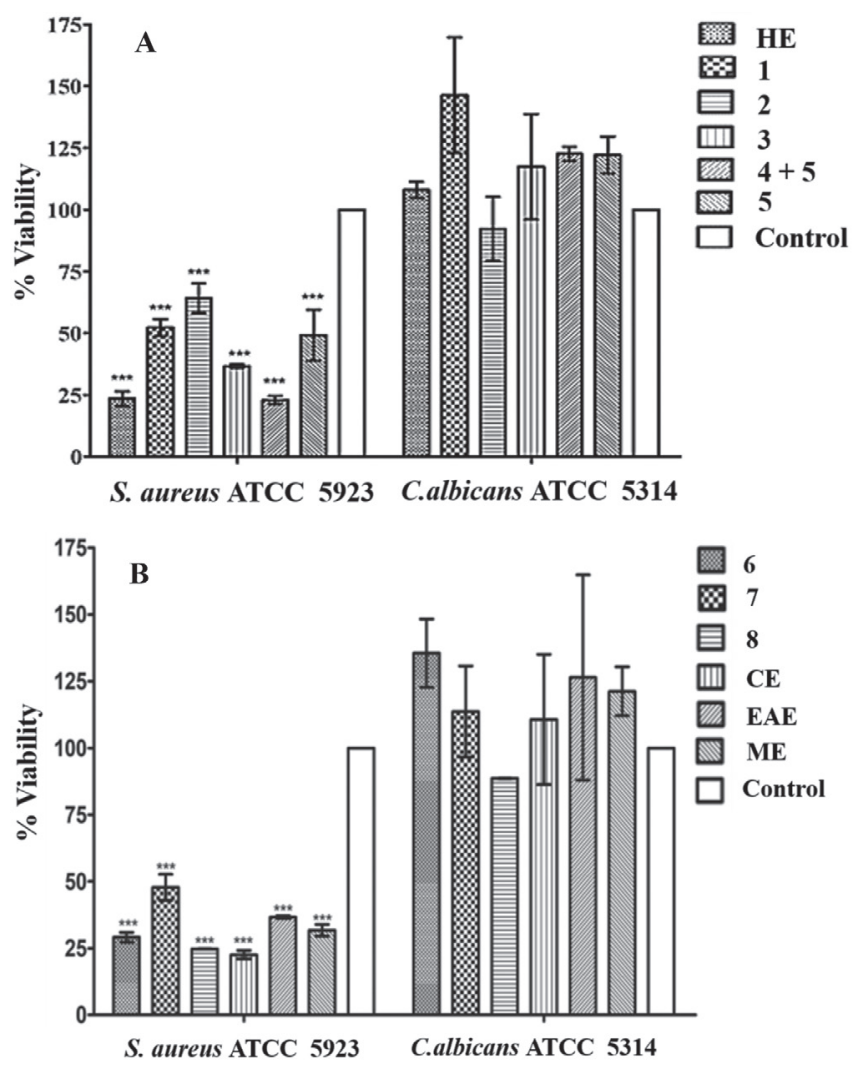

Figure 2. Percent viability of S. aureus MRSA (ATCC 25923) and C. albicans (ATCC SC5314) treated with substances from Maytenus distichophylla roots. A) $\mathrm{HE}=$ hexane extract, $\mathbf{1}=$ friedelan-3-one, $2=\beta$-sitosterol, $\mathbf{3}=3$-oxoolean-9(11),12-diene, $4+5=[($ mixture of pristimerin $(4)+$ rigidenol $(5)]$, $5=$ Rigidenol. B) $\mathbf{6}=30$-hydroxylup-20(29)-en-3-one, 7 = friedelane-3,7dione, $8=$ tingenone, $C E=$ chloroform, $E A E=$ ethyl acetate and $M E=$ methanol extracts. DMSO = positive control

anti-carcinogenic ${ }^{64}$ or antiretroviral ${ }^{62}$ agents, different compounds from plants have been used as a starting point for development of new drugs with social and economic potential. In this context, the cytotoxic activities of compounds and extracts from $M$. distichophylla roots were evaluated against leukemic cells through the $\mathrm{IC}_{50}$ value calculated by the MTT assay. The samples exhibited in vitro cytotoxicity against K562 chronic myeloid leukemia cells (1: $14.70 \mu \mathrm{gLL}^{-1} ; 2: 15.08 \mu \mathrm{g} \mathrm{mL}^{-1}$; and 8: $12.56 \mu \mathrm{g} \mathrm{mL}^{-1}$ ) and

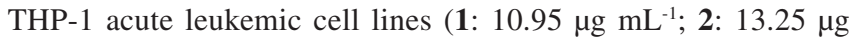
$\mathrm{mL}^{-1}$; and 8: $9.80 \mu \mathrm{g} \mathrm{mL}^{-1}$ ) (Table 1). According to the results, the cytotoxic activities of compounds 1, 2 and $\mathbf{8}$ induced activity against the THP-1 cell, similar to etoposide, which is an inhibitor of DNA synthesis that acts through stabilization of type II topoisomeraseDNA complexes, preventing joining of single- and double-strand DNA breaks. ${ }^{65,66}$ On the other hand, the compound $\mathbf{8}$ showed similar cytotoxic activity $(p>0.05)$ to that of the etoposide in the K562 line (Table 1).

In addition to low cytotoxic activities, the compounds must show a higher selectivity index than the etoposide (Table 2). It may be noted that compounds $\mathbf{1}$ to $\mathbf{8}$ have better selectivity index than the etoposide, which is considered very cytotoxic to the studied cells. Therefore, the compounds with better cytotoxic activity and better SI are the compounds 1, 2, and 8 (THP-1 cells) and $\mathbf{2}$ and 8 (K562 cells) (Table 2).

Compounds 1, 2 and $\mathbf{8}$ showed cytotoxic activity and selectivity against THP-1 and K562 cells, being considered as candidates for new studies to elucidate its mechanisms of inhibition. 
Table 1. Cytotoxic activity of $M$. distichophylla compounds, extracts and etoposide against THP-1, K562 and PBMC cell lines

\begin{tabular}{lccc}
\hline \multirow{2}{*}{ Sample } & \multicolumn{3}{c}{$\mathrm{IC}_{50}\left(\mu \mathrm{g} \mathrm{mL}^{-1}\right) \pm \mathrm{SD} *$} \\
\cline { 2 - 4 } $\mathbf{1}$ & $\mathrm{THP}-1$ & $\mathrm{~K} 562$ & $\mathrm{PBMC}$ \\
$\mathbf{2}$ & $10.95 \pm 1.04$ & $14.70 \pm 1.86$ & $55.68 \pm 2.87$ \\
$\mathbf{3}$ & $25.25 \pm 1.55$ & $15.08 \pm 1.92$ & $67.90 \pm 2.51$ \\
$\mathbf{4 + 5}$ & $51.02 \pm 2.15$ & $42.89 \pm 2.88$ & $92.58 \pm 3.78$ \\
$\mathbf{5}$ & $66.37 \pm 3.02$ & $78.09 \pm 3.92$ & $121.11 \pm 5.02$ \\
$\mathbf{6}$ & $31.04 \pm 2.30$ & $33.60 \pm 2.10$ & $76.22 \pm 3.58$ \\
$\mathbf{7}$ & $25.44 \pm 1.55$ & $30.88 \pm 2.45$ & $80.20 \pm 4.11$ \\
$\mathbf{8}$ & $9.80 \pm 1.10$ & $12.56 \pm 58$ & $50.12 \pm 3.57$ \\
HE & $88.20 \pm 3.90$ & $92.50 \pm 3.20$ & $110.08 \pm 4.12$ \\
CE & $29.20 \pm 2.08$ & $34.50 \pm 2.44$ & $76.62 \pm 3.50$ \\
EAE & $50.15 \pm 3.29$ & $68.80 \pm 3.56$ & $80.65 \pm 4.02$ \\
ME & $45.70 \pm 3.17$ & $52.15 \pm 3.01$ & $78.70 \pm 4.76$ \\
Etoposide & $12.04 \pm 2.32$ & $9.11 \pm 1.33$ & $8.63 \pm 0.13$ \\
P value & $<0.05^{\mathrm{a}}$ & $<0.05^{\mathrm{c}}$ & $<0.05^{\mathrm{e}}$ \\
& $>0.05^{\mathrm{b}}$ & $>0.05^{\mathrm{d}}$ & \\
\hline
\end{tabular}

*Values presented as average \pm standard deviation. a: THP-1, Etoposide versus HE, 3-8, CE, EAE and ME; b: THP-1, Etoposide vs 1, 2 and 8; c: K562, Etoposide $v s$ HE-7, CE, EAE and ME; d: K562, Etoposide vs 8, e: PBMC, Etoposide $v s$ all compounds tested. $\mathbf{1}=$ friedelan-3-one, $\mathbf{2}=\beta$-sitosterol, $\mathbf{3}=3$-oxo-olean-9(11),12-diene, $\mathbf{4}+\mathbf{5}=[$ (mixture of pristimerin $(\mathbf{4})+$ rigidenol (5) ], 5 = rigidenol, $\mathbf{6}=$ 30-hydroxylup-20(29)-en-3-one, 7 = friedelane-3,7dione, $\mathbf{8}=$ tingenone. $\mathrm{HE}=$ hexane, $\mathrm{CE}=$ chloroform, $\mathrm{EAE}=$ ethyl acetate and $\mathrm{ME}=$ methanol extracts.

Table 2. Selectivity index determined for compounds and extracts from $M$. distichophylla for THP-1 and K562 cells

\begin{tabular}{lcc}
\hline \multirow{2}{*}{ Sample } & \multicolumn{2}{c}{ Selectivity index for cells } \\
\cline { 2 - 3 } $\mathbf{1}$ & THP-1 & K562 \\
$\mathbf{2}$ & 5.08 & 3.79 \\
$\mathbf{3}$ & 5.12 & 4.50 \\
$\mathbf{4 + 5}$ & 3.46 & 3.05 \\
$\mathbf{5}$ & 1.81 & 2.16 \\
$\mathbf{6}$ & 1.82 & 1.55 \\
$\mathbf{7}$ & 2.45 & 2.27 \\
$\mathbf{8}$ & 3.15 & 2.60 \\
HE & 5.12 & 4.00 \\
CE & 1.25 & 1.19 \\
EAE & 2.62 & 2.22 \\
ME & 1.61 & 1.17 \\
Etoposide & 1.72 & 1.51 \\
\hline
\end{tabular}

$\mathbf{1}=$ friedelan-3-one, $\mathbf{2}=\beta$-sitosterol, $\mathbf{3}=3$-oxo-olean-9(11),12-diene, $\mathbf{4}+\mathbf{5}=[($ mixture of pristimerin $(\mathbf{4})+$ rigidenol $(\mathbf{5})], \mathbf{5}=($ Rigidenol $)$, $\mathbf{6}=30$-hydroxylup-20(29)-en-3-one, $7=$ friedelane-3,7-dione, $\mathbf{8}=$ tingenone. $\mathrm{HE}=$ hexane, $\mathrm{CE}=$ chloroform, $\mathrm{EAE}=$ ethyl acetate and $\mathrm{ME}=$ methanol extracts.

\section{Toxicity to Caenorhabditis elegans}

In the present work, extracts and compounds of M. distichophylla roots were tested using the $C$. elegans model ${ }^{67}$ Firstly, the samples were tested to verify if are toxic to the L1 larvae, that is the most vulnerable development stage of the $C$. elegans. Thus, the acute (24 h exposition) toxicity of samples from $M$. distichophylla roots to C. elegans L1 larvae was evaluated by the MTT method. For some samples from $M$. distichophylla, specially for $\mathbf{6}$ and $\mathbf{8}$, an increase in the blue color of MTT-formazan was observed, suggesting proliferation of C. elegans. However, as L1 larvae do not multiply, values higher than $100 \%$ indicate a larger number of nematodes in the wells, leading to overestimation of the spectrophotometric reading in acute toxicity evaluation of the compounds on C. elegans. Thus, no toxicity induced by the samples on L1 larvae was detected under the experimental conditions used (Figure 3).

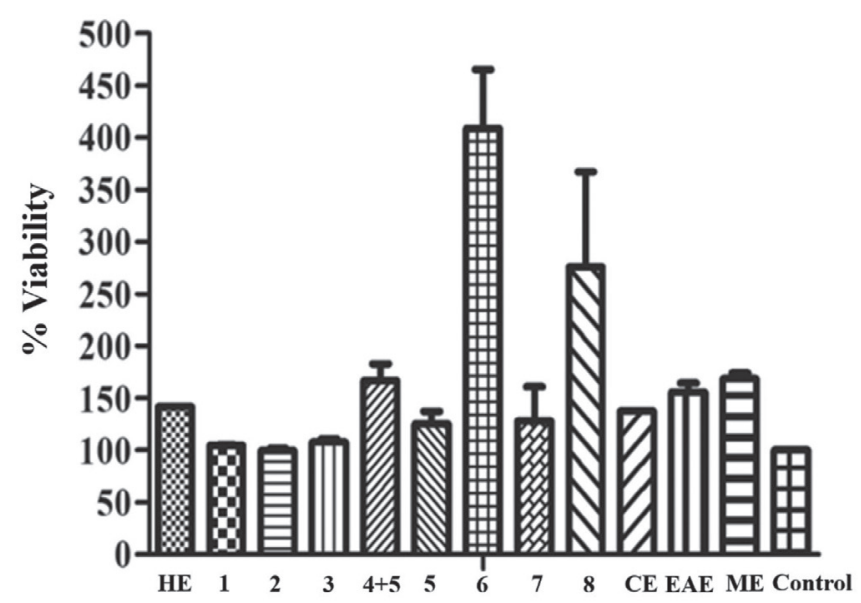

Figure 3. Acute toxicity (24h) evaluation for C. elegans L1 larvae of extracts and compounds from Maytenus distichophylla roots. HE = hexane, $C E=$ chloroform, $E A E=$ ethyl acetate and $M E=$ methanol extracts . $\boldsymbol{1}$ = friedelan-3-one, $\mathbf{2}=\beta$-sitosterol, 3 = 3-oxo-olean-9(11),12-diene, $\mathbf{4}+\mathbf{5}=[($ mixture of pristimerin $(4)+$ rigidenol $(5)], 5=$ rigidenol, $\mathbf{6}=30$-hydroxylup-20(29)-en-3-one, $7=$ friedelane-3,7-dione, $8=$ tingenone . Control $=$ DMSO

The chronic toxicity and survival of adult (L4) C. elegans can be evaluated through the median lethal time $\left(\mathrm{LT}_{50}\right)$, which represents $50 \%$ lethality induced by a specific concentration of a substance, observed after specific period of time. ${ }^{53}$ So, the $\mathrm{LT}_{50}$ of $C$. elegans observed after its exposure to extracts and compounds from Maytenus distichophylla roots was determined (Figure 4). Compounds which show high $\mathrm{LT}_{50}$ values after 5 days are considered to possess therapeutic potential..$^{56}$ This property can be assigned to hexane extract (HE) (8 days) and to $\mathbf{4 + 5}$ mixture (6 days) (Figure 4 ). The other samples from $M$. distichophylla roots showed values of time until death $\mathrm{LT}_{50} \leq 5$ days at the tested concentrations, indicating that chronic exposure to them affects the viability of $C$. elegans. Therefore, these substances have nematicide properties that make them suitable for parasitology applications.

In the chronic trials, adult (L4) C. elegans were used to verify if toxic effects are induced by the samples of $M$. distichophylla, after an exposure time. Thus, survival curves of C. elegans (L4 larvae) normally fed with E. coli OP50 and in the presence of samples at the maximum concentration tested were established (Figure 5). It was observed that all extracts and compounds, after a chronic exposure, reduced significantly the C. elegans (L4 larvae) survival (Figure 5). 


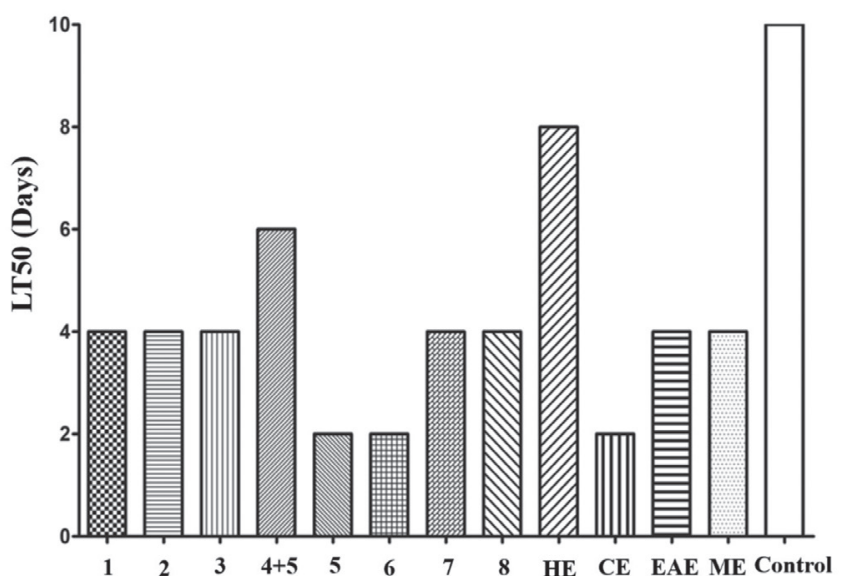

Figure 4. Median lethal time $\left(L T_{50}\right)$ determined after exposure of C. elegans to compounds and extracts from Maytenus distichophylla roots. $\mathbf{1}=$ friedelan3-one, $2=\beta$-sitosterol, 3 = 3-oxo-olean-9(11),12-diene, $4+5=[($ mixture of pristimerin $(\mathbf{4})+$ rigidenol $(\mathbf{5})], \mathbf{5}=$ rigidenol, $\mathbf{6}=30$-hydroxylup-20(29)-en-3one, $7=$ friedelane-3,7-dione, $8=$ tingenone. $H E=$ hexane,$C E=$ chloroform, $E A E=$ ethyl acetate and $M E=$ methanol extracts. DMSO = positive Control

Compound 1 (friedelan-3-one), 2 ( $\beta$-sitosterol), 3 (3-oxo-olean9(11),12-diene), 5 (rigidenol), 6 (30-hydroxylup-20(29)-en-3-one), 7 (friedelane-3,7-dione) and $\mathbf{8}$ (tingenone), and the HE, CE, EAE and ME extracts showed a potent nematicidal activity, reducing more than $60 \%$ the $\mathrm{LT}_{50}$ of C. elegans and thus decreasing worm's survival (Figure 5). More relevant are rigidenol (5), 30-hydroxylup-20(29)en-3-one (6) and ethyl acetate extract (EAE) of M. distichophylla that killed more than $80 \%$ of the worm population and thus, these samples are interesting candidates to more detailed studies related to mechanisms of nematocide action. The nematocide potential found could be explored in parasitological studies.

\section{CONCLUSIONS}

Nine compounds were isolated from $M$. distichophylla roots, being seven pentacyclic triterpenes, one steroid and one triacylglycerol. Among the isolated compounds, seven ( 3 to 9 ) were described for the first time from $M$. distichophylla. The effects of the compounds on the viability of $S$. aureus together with the non-toxicity of the compounds for $C$. elegans larvae constitute good prediction for the use of hexane extract and the mixture of $\mathbf{4 + 5}$ [pristimerin (4) + rigidenol (5)], in researches involving in vivo bacterial infections. Compounds 1, 2 and $\mathbf{8}$ showed potential cytotoxic activity and selectivity against THP-1 and K562 cells.

\section{SUPPLEMENTARY MATERIAL}

The Figures 1S-25S present spectral data of compounds isolated of hexane and chloroform extracts of the roots of Maytenus distichophylla. This supplementary material is available free of charge at http://quimicanova.sbq.org.br, as PDF file.

\section{ACKNOWLEDGMENTS}

The authors thank Conselho Nacional de Desenvolvimento Científico e Tecnológico (CNPq), Coordenação de Aperfeiçoamento de Pessoal de Nível Superior (CAPES) and Fundação de Amparo à Pesquisa de Minas Gerais for their financial support. The authors also thank Dr. Guadalupe E. L. de Macedo (UESB) for the botanical identification of M. distichophylla.
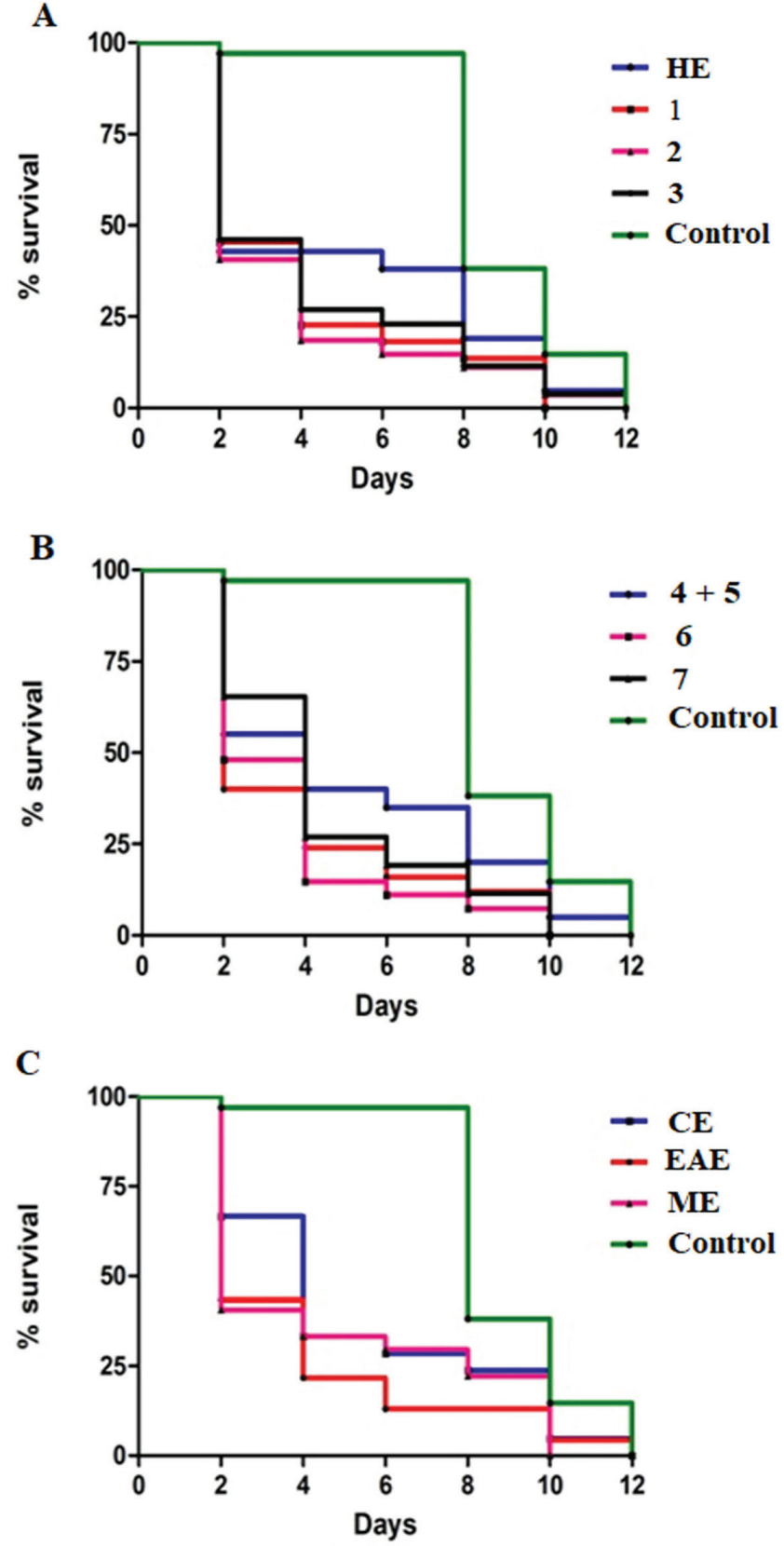

Figure 5. Effect on the C. elegans survival, after treatment with extracts and compounds from $M$. distichophylla roots. $\mathbf{1}=$ friedelan-3-one, $\mathbf{2}=\beta$-sitosterol, $3=3$-oxo-olean-9(11),12-diene, $4+5=[($ mixture of pristimerin $(4)+$ rigidenol (5)], 5 = rigidenol, $\mathbf{6}=30$-hydroxylup-20(29)-en-3-one, 7 = friedelane-3,7dione, $8=$ tingenone. $H E=$ hexane, $C E=$ chloroform, $E A E=$ ethyl acetate and $M E=$ methanol extracts. DMSO = positive control

\section{REFERENCES}

1. Yunes, R. A.; Cechinel Filho, V.; Breve Análise Histórica da Química de Plantas Medicinais: Sua Importância na Atual Concepção de Fármaco Segundo os Paradigmas Ocidental e Oriental. Plantas Medicinais sob a Ótica da Química Medicinal Moderna. Argos: Chapecó, 17-46, 2001.

2. Simmons, M. P.; Savolainen, V.; Clevinger, C. C.; Archer, R. H.; Davis, J.; Mol. Phylogenet. Evol. 2001, 19, 353.

3. Mokoka, T. A.; Mcgaw, L. J.; Mdee, L. K.; Bagla, V. P.; Iwalewa, E. O.; Eloff, J. N.; BMC Complementary Altern. Med. 2013, 13, 111.

4. Niero, R.; Andrade, S. F.; Filho, V. C. A.; Curr. Pharm. Design 2011, 17, 1851. 
5. da Silva, G.; Taniça, M.; Rocha, J.; Serrano, R.; Gomes, E. T.; Sepodes, B.; Silva, O.; Hum. Exp. Toxicol. 2011, 30, 693.

6. Patocka, J.; J. Appl. Biomed. 2003, 1, 7.

7. Yu, D.; Sakurai, Y.; Chen, C-H.; Chang, F-R.; Huang, L.; Kashiwada, Y.; Lee, K-H.; J. Med. Chem. 2006, 49, 5462.

8. Qian, K.; Kuo, R-Y.; Chen, C-H.; Huang, L.; Morris-Natschke, S. L.; Lee, K-H.; J. Med. Chem. 2010, 53, 3133.

9. Paduch, R.; Kandefer-Szerszen, M.; Mini-Rev. Org. Chem. 2014, 11, 262.

10. Rodrigues, V. G.; Duarte, L. P.; Silva, R. R.; Silva, G. D. F.; MercadanteSimões, M. O.; Takahashi; J. A.; Matildes, B. L. G.; Fonseca, T. H. S.; Gomes, M. A.; Vieira Filho; S. A.; Quim. Nova 2015, 38, 237.

11. Chiozem, D. D.; Trinh-Van_D. H.; Wansi, J. D.; Djama, C. M.; Fannang, V. S.; Seguin, E.; Tillequin, F.; Wandji, J.; Chem. Pharm. Bull. 2009, 57, 1119.

12. González-Coloma, A.; López-Balboa, C.; Santana, O.; Reina, M.; Fraga B. M.; Phytochem. Rev. 2011, 10, 245.

13. Kayser, O.; Kilderlen, A. F.; Croft, S. L.; Parasitol. Res. 2003, 90, 55.

14. Andrade, S. F.; Comunello, E.; Noldin, V. F.; Monache, F. D.; Cechinel Filho, V.; Niero, R.; Arch. Pharmacol. Res. 2008, 31, 41.

15. Veloso, C. C.; Rodrigues, V. G.; Azevedo, A. O.; Oliveira, C. C.; Gomides, L. F.; Duarte, L. P.; Duarte, I. D.; Klein, A.; Perez, A. C.; J. Med. Plants Res. 2014, 8, 68.

16. Longhi-Balbinot, D. T.; Martins, D. F.; Lanznaster, D.; Silva, M. D.; Facundo, V. A.; Santos, A. R. S.; Eur. J. Pharmacol. 2011, 653, 32.

17. Martins, M. V.; Estevam, C. S.; Santos, A. L. L. M.; Dias, A. S.; Cupertino-Da-Silva, Y. K.; Araújo-Júnior, J. X.; Miranda, A. L. P.; Barreiro, E. J.; Pizza, C.; Piacente, S.; Montoro, P.; Quintans- Júnior, L. J.; Araujo, B. S.; Alexandre-Moreira, M. S.; Sant'Ana, A. E. G.; Rev. Bras. Farmacogn. 2012, 22, 598.

18. Veloso, C. C.; Soares, G. L.; Perez, A. C.; Rodrigues, V. G.; Silva, F. C.; Rev. Bras. Farmacogn. 2017, 27, 533.

19. Pereira, R. C. G.; Soares, D. C. F.; Oliveira, D. C. P.; De Sousa, G. F.; Vieira Filho, S. A.; Mercadante-Simões M. O.; Lula I.; Silva-Cunha A.; Duarte L. P.; Mag. Res. Chem. 2018, 56, 360.

20. Gomes, J. P. M.; Cardoso, C. R. P.; Varanda, E. A.; Molina, J-M.; Fernandez, M. F.; Olea, N.; Arlos, I. Z.; Vilegas, W.; Rev. Bras. Farmacogn. 2011, 21, 963.

21. Sousa, G. F. D.; Soares, D. C. F.; Mussel, W. D. N.; Pompeu, N. F. E.; Silva, G. D. D. F.; Vieira Filho, S. A.; Duarte, L. P.; J. Braz. Chem. Soc. 2014, 25, 1338.

22. Saleem, M.; Nazir, M.; Ali, M. S.; Hussain, H.; Lee, Y. S.; Riaz, N.; Jabbar, A.; Nat. Prod. Rep. 2010, 27, 238.

23. Carvalho-Okano, R. M.; Doctoral Thesis, Instituto de Biologia, Universidade de Campinas, Brasil, 1992.

24. Santos, V. L.; Costa, V. B. M.; Agra, M. F.; Silva, B. A.; Batista, L. M.; Rev. Bras. Farmacogn. 2007, 17, 336.

25. Magalhães, C. G.; Ferrari, F. C.; Guimarães, D. A. S.; Silva, G. D. F.; Duarte, L. P.; Figueiredo, R. C.; Vieira Filho, S. A.; Rev. Bras. Farmacogn. 2011, 21, 415.

26. Jesus, J. A.; Lago, J. H. G.; Laurenti, M. D.; Yamamoto, E. S.; Passero, L. F. D.; Evid. Based Complement. Alternat. Med. (eCAM). 2015, Article ID 620472.

27. Cartaxo, S. L.; Souza, M. M. A.; Albuquerque, U. P.; J. Ethnopharmacol. 2010, 131, 326.

28. Duarte, M. C.; Tavares, J. F.; Madeiro, S. A. L.; Costa, V. C. O.; Filho, J. M. B.; Agra, M. F.; Filho, R. B.; Silva, M. S.; J. Braz. Chem. Soc. 2013, 24, 1697.

29. Ferreira, F. L.; Rodrigues, V. G.; Silva, F. C.; Matildes, B. L. G.; Takahashi, J. A.; Silva, G. D. F.; Duarte, L. P.; Oliveira, D. M.; Vieira Filho, S. A.; Rev. Bras. Farmacogn. 2017, 27, 471.

30. Matos F. J. A.; Introdução à Fitoquímica Experimental. UFC: Fortaleza, 1988, p. 129.
31. Wagner, H.; Bladt, S.; Plant Drug Analysis: A Thin Layer Chromatography Atlas, Springer: Berlin, 1996, p. 384.

32. Hjertstedt, J. L.; Hahn, B. L.; Kos, W. L.; Sohnle, P. G.; Mycoses 1998, $41,487$.

33. Mosmann, T.; J. Immunol. Methods 1983, 65, 55.

34. Pohlit, A. M.; Tigre, R. F.; Cavalcanti, B. C.; Moraes, M. O.; CostaLotufo, L. V.; Moraes, M. E. A.; dos Santos, E. V. M.; Morais, S. K. R.; Nunomura, S. M.; Pessoa, C.; Pharm. Biol. 2007, 45, 429.

35. Brenner, S.; Genetics 1974, 77, 71.

36. Porta-De-La-Riva, M.; Fontrodona, L.; Villanueva, A.; Cerón, J.; J. Vis. Exp. 2012, 10, e4019.

37. Lionaki, E.; Tavernarakis, N.; Meth. Molec. Biol. 2013, 965, 485.

38. James, C. E.; Davey, M. W.; Parasitol. Res. 2007, 101, 975.

39. Mitchell, D. H.; Stiles, J. W.; Santelli, J.; Sanadi, D. R.; J. Gerontol. 1979, 34, 28.

40. Huang, X.; Li, D.; Xi, L.; Mylonakis, E.; PLoS One 2014, 9, e108764.

41. Mahato, S. B.; Kundu, A. P.; Phytochemistry 1994, 37, 1517.

42. Kitajima, J.; Kimizuka, K.; Tanaka, Y.; Chem. Pharm. Bull. 1998, 46, 1408.

43. Barnes R. A.; Perlera A. L.; Scofield T. C. V.; Fieho R. B.; Pinto A. C.; Chem. Pharm. Bull. 1984, 32, 3674.

44. Fernando H. C.; Gunatilaka A. A. L.; Tezuka Y.; Kikuchi T.; Tetrahedron $\mathbf{1 9 8 9}, 45,5867$

45. González, A. G.; Fraga, B. M.; González, P.; Marta, M.; Monache, F. D.; Marini-Bettolo, G. B.; Mello, J. F.; Goncalves, O.; Phytochemistry 1982, 21,470 .

46. Tinto W. F.; Blair L. C.; Ali A.; Reynolds W. F.; McLean S.; J. Nat. Prod. 1992, 55, 395.

47. Patra, A.; Chaudhuri, S. K.; Magn. Reson. Chem. 1987, 25, 95.

48. Sotanaphun, U.; Suttisri, R.; Lipipun, V.; Bavovada, R.; Phytochemistry 1998, 49, 1749 .

49. Gunstone, F. D.; Harwood, J. L.; Dijkstra, A. J.; The Lipid Handbook, CRC Press, Taylor \& Francis Group: Boca Raton, 2007, p. 471.

50. Queiroga, C. L.; Silva, G. F.; Dias, P. C.; Possenti, A.; Carvalho, J. E.; J. Ethnopharm. 2000, 72, 465.

51. Araújo Júnior, R. F.; Oliveira, A. L. C. S. L.; Pessoa, J. B.; Garcia, V. B.; Guerra, G. C. B.; Soares, L. A. L.; Souza, T. P.; Petrovick, P. R.; Araújo, A. A.; Experim. Biol. Med. 2013, 238, 1251.

52. Miranda, R. R. S.; Silva, G. D. F.; Duarte, L. P.; Fortes, I. C. P.; Vieira Filho, S. A.; Mag. Res. Chem. 2006, 44, 127.

53. Sidorov, R. A.; Zhukov, A. V.; Pchelkin, V. P.; Vereshchagin, A. G.; Tsydendambaev, V. D.; Chem. Biodiv. 2013, 10, 976.

54. Silva, F. C.; Duarte, L. P.; Silva, G. D. F.; Vieira Filho, S. A.; Lula, I. S.; Takahashi, J. A.; Sallum, W. S. T.; J. Braz. Chem. Soc. 2011, $22,943$.

55. Oliveira, D. M.; Silva, G. D. F.; Duarte, L. P.; Vieira Filho, S. A.; Chem. Biochem. Syst. Ecol. 2006, 34, 661.

56. Gonzalez, A. G.; Ferro, E. E.; Ravelo, A. G.; Phytochemistry, 1987, 26, 2785.

57. Silva, R. S. S.; Silva, G. D. F.; Barbosa, L. C. A.; Duarte, L. P.; Vieira Filho, S. A.; Helv. Chim. Acta 2005, 88, 1102.

58. Wang, Y.; Zhou, Y.; Zhou, H.; Jia, G.; Liu, J.; Han, B.; Cheng, Z.; Jiang, H.; Pan, S.; Sun, B.; PLoS One 2012, 7, e43826.

59. Lee, J. S.; Yoon, I. S.; Lee, M. S.; Cha, E. Y.; Thuong, P. T.; Diep, T. T.; Kim, J. R.; Biol. Pharm. Bull. 2013, 36, 316.

60. Bashir A. Y.; Hozeifa M. H.; Lu-Yong Z.; Zhen-Zhou J.; Curr. Cancer Drug Targets 2017, 17, 100.

61. Reyes, C. P.; Núñez, M. J.; Jiménez, I. A.; Busserolles, J.; Alcaraz, M. J.; Bazzocchi, I. L.; Bioorg. Med. Chem. 2006, 14, 1573.

62. Callies, O.; Bedoya, L.; Beltrán, M.; Muñoz, A.; Obregón, P.; Osorio, A.; Jiménez, I.; Alcamí, J.; Bazzocchi, I.; J. Nat. Prod. 2015, 78, 1045.

63. Magalhães, C. G.; Silva, G. D. F.; Duarte, L. P.; Takahashi, J. A.; Santos, V. R.; Figueiredo, R. C.; Vieira Filho, S. A.; Rev. Virtual Quim. 2016, 8, 1524 
64. Okoye, F. B. C.; Debbab, A.; Wray, V.; Esimone, C. O.; Osadebe, P. O.; Proksch, P.; Tetrahedron Lett. 2014, 55, 3756.

65. Hande, K. R.; Semin. Oncol. 1992, 19, 3.
66. Fleming, R. A.; Miller, A. A.; Stewart, C. F.; Clin. Pharm. 1989, 8, 274.

67. Dengg, M.; Van Meel, J. C.; J. Pharmacol. Toxicol. Methods 2004, 50, 209. 